\title{
Large body size variation is associated with low communication success in tandem running ants
}

\author{
Thomas Wagner $^{1} \cdot$ Lena Bachenberg $^{1} \cdot$ Simone M. Glaser ${ }^{1} \cdot$ Avgousta Oikonomou $^{1} \cdot$ Melissa Linn $^{1}$. \\ Christoph Grüter ${ }^{1,2}$
}

Received: 19 February 2020 / Revised: 14 October 2020 / Accepted: 26 November 2020 / Published online: 11 December 2020

(C) The Author(s) 2020

\begin{abstract}
Diversity in animal groups is often assumed to increase group performance. In insect colonies, genetic, behavioural and morphological variation among workers can improve colony functioning and resilience. However, it has been hypothesized that during communication processes, differences between workers, e.g. in body size, could also have negative effects. Tandem running is a common recruitment strategy in ants and allows a leader to guide a nestmate follower to resources. A substantial proportion of tandem runs fail because leader and follower lose contact. Using the ant Temnothorax nylanderi as a model system, we tested the hypothesis that tandem running success is impaired if leader and follower differ in size. Indeed, we found that the success rate of tandem pairs drops considerably as size variation increases: tandem runs were unsuccessful when the leaderfollower size difference exceeded $10 \%$, whereas $\sim 80 \%$ of tandem runs were successful when ants differed less than $5 \%$ in body length. Possible explanations are that size differences are linked to differences in walking speed or sensory perception. Ants did not choose partners of similar size, but extranidal workers were larger than intranidal workers, which could reduce recruitment mistakes because it reduced the chance that very large and very small ants perform tandem runs together. Our results suggest that phenotypic differences between interacting workers can have negative effects on the efficiency of communication processes. Whether phenotypic variation has positive or negative effects is likely to depend on the task and the phenotypic trait that shows variation.
\end{abstract}

\section{Significance statement}

Diversity is often assumed to increase colony performance in social insects. However, phenotypic differences among workers could also have negative effects, e.g. during communication. Tandem running is a common recruitment strategy in ants, but tandem runs often fail when ants lose contact. We used the ant Temnothorax nylanderi to test the hypothesis that body size differences between tandem leader and follower impair tandem communication. We show that the success rate of tandem pairs drops considerably as size variation increases, possibly because ants of varying size also differ in walking speed. Our study supports the hypothesis that phenotypic variation among workers might not always be beneficial and can negatively impact the efficiency of communication processes.

Keywords Recruitment $\cdot$ Teaching $\cdot$ Tandem running $\cdot$ Social learning $\cdot$ Temnothorax nylanderi

Communicated by W. Hughes

Christoph Grüter

c.grueter@bristol.ac.uk

1 Institute of Organismic and Molecular Evolution, Johannes Gutenberg University, Biozentrum I, Hanns Dieter Hüsch Weg 15, 55128 Mainz, Germany

2 Present address: School of Biological Sciences, University of Bristol, 24 Tyndall Avenue, Bristol BS8 1TQ, UK

\section{Introduction}

Social groups consist of individuals that differ from each other in a number of ways. For instance, people working in a company may differ in experience, training, gender, ethnicity or skills and this diversity can affect group performance and success. Scientists interested in organizational theory have found that group diversity often has positive effects on group performance, most likely because diverse groups possess a broader range of knowledge, experience, personality, skills 
and abilities (Horwitz and Horwitz 2007; van Knippenberg and Schippers 2007). For instance, more diverse scientific collaborations produce publications of greater impact (Freeman and Huang 2015; Alshebli et al. 2018), more ethnically diverse markets show lower risks of price bubbles (Levine et al. 2014) and companies with greater gender diversity in corporate leadership positions are more successful (Noland et al. 2016). As a result, organizations may compose teams to incorporate differences in functional, ethnic or educational background (van Knippenberg and Schippers 2007).

Insect colonies consist of many individuals that may appear similar or even identical to the casual observer, but closer examination readily reveals that the members of a colony differ in many ways, including their morphology, behaviour, experience or genetic background (Wilson 1971; Oster and Wilson 1978; Hölldobler and Wilson 2009). Several studies have found that differences among workers promote colony success. For example, colonies that show greater behavioural variation (e.g. because they are genetically more diverse) have been shown to collect food more successfully, respond better to environmental perturbations or produce more brood (Jones et al. 2004; Mattila and Seeley 2007; Oldroyd and Fewell 2007; Modlmeier and Foitzik 2011). Workers of many species also differ in their morphology, and this morphological variation is closely tied to division of labor in many species (ants: Hölldobler and Wilson 2009; bumblebees: Goulson et al. 2002; stingless bees: Grüter et al. 2017a, Baudier et al. 2019; termites: Tian and Zhou 2014). Having different worker types for different tasks is likely to increase group performance because different worker types are more efficient at performing particular tasks (Oster and Wilson 1978; Powell and Franks 2005; Mertl and Traniello 2009; Grüter et al. 2012, 2017b; Powell 2016). Even in species with gradual variation, i.e. without distinct morphological castes, colonies with a larger worker size range often seem more successful (Porter and Tschinkel 1985; Beshers and Traniello 1994; Billick 2002; Billick and Carter 2007, but see Jandt and Dornhaus 2014; Colin et al. 2017; Honorio et al. 2020). In most cases, this intracolonial variation is an example of phenotypic plasticity, where the phenotypic differences are generated by variation in environmental factors (e.g. food quantity, temperature), rather than differences in genotype (Oster and Wilson 1978; Sumner et al. 2006; Segers et al. 2015; Molet et al. 2017).

Group diversity can also have adverse effects on consensus decision-making, group functioning and increase intragroup conflicts (Horwitz and Horwitz 2007; van Knippenberg and Schippers 2007). In humans, for instance, individuals might prefer to interact with more similar individuals (Horwitz and Horwitz 2007). In social insect colonies, there could also be circumstances where differences among cooperating workers have negative effects on group performance. Waddington et al. (1986) and Waddington (1989) argued that worker size variation reduces the efficiency of communication in social bees. If signal producers and receivers differ in morphology (and their sensory systems), the communication of misinformation or impaired information transfer could become more likely. For instance, honeybees of different sizes might judge distances to food sources differentially, which could lead to different interpretations of distance information provided during waggle dancing. There is indeed evidence that honeybee (Apis mellifera) colonies with larger body size variation collect less nectar (Waddington 1989) and stingless bees with more sophisticated communication show lower within colony size variation (Waddington et al. 1986). The former study also found that honeybee dancers tended to interact with bees of similar size. Waddington et al. (1986) argue that negative effects of size differences on communication could explain why colonies of the highly eusocial honeybees and stingless bees, which often use sophisticated communication during foraging, are less morphologically variable than the primitively eusocial bumblebees, which use simpler methods of communication (Dornhaus and Chittka 1999). However, the potential disadvantages of worker size variation for communication processes in insect societies have received little attention and, as far as we know, we still lack evidence that body size differences among interacting individuals indeed affect communication efficiency.

A recruitment behaviour that relies on communication and that could be negatively affected by body size differences is tandem running, which is relatively common in ant species with small colony sizes (so far described in $\sim 40$ species) (Beckers et al. 1989; Franklin 2014; Grüter et al. 2018; tandem running by reproductives is also found in some termites, e.g. Matsuura et al. 2002). During a tandem run, a leader with information about the location of a resource slowly guides a nestmate to a food source or a nest site. Contact between the leader and the follower is maintained by frequent physical interactions and short-range pheromones (Möglich et al. 1974; Basari et al. 2014a). This behaviour has been considered a case of animal teaching because leaders actively facilitate learning in a nestmate while also incurring costs (Franks and Richardson 2006). Contact losses are common during tandem runs (and they might help followers to acquire navigational information), but break-ups are often prevented by leaders waiting for their partner while the latter searches for her leader (Franks and Richardson 2006; Richardson et al. 2007). Nonetheless, a substantial proportion of tandem runs break up before reaching the goal (e.g. $\sim 19 \%$ in Temnothorax nylanderi, Glaser and Grüter 2018; $23 \%$ in Pachycondyla harpax, Grüter et al. 2018; 50\% in Cardiocondyla venustula, Wilson 1959; up to $70 \%$ in Temnothorax rugatulus, Pratt 2008). Break-ups are costly in terms of time and could leave lost followers in dangerous areas. 
We studied tandem running during colony emigrations in Temnothorax nylanderi, a species with moderate size variation (Molet et al. 2017), and tested the hypothesis that the body size difference between leaders and followers affects the efficiency of recruitment. Specifically, we tested the prediction that size differences between interacting partners have a negative effect on the success rate. To obtain a better understanding of body size variation in this population, we also quantified the body size distribution in several colonies and tested whether extranidal workers (potential scouts for nest sites or food) are larger than intranidal workers as was found in two other species from the same genus (Herbers and Cunningham 1983; Westling et al. 2014). Finally, we measured the relationship between body size and the walking speed of an ant.

\section{Methods}

\section{Study site and species}

Temnothorax nylanderi colonies were collected from acorns and decaying branches in the Lenneberg forest $\left(50^{\circ} 00^{\prime} 44.2\right.$ $\mathrm{N}, 8^{\circ} 10^{\prime} 57.8 \mathrm{E}$ ) near Mainz in Germany in 2015 (part 1), 2016 (part 2), 2017 (part 4) and 2018 (part 3). Back in the laboratory, colonies were kept in nests made up of two microscope slides $(50 \mathrm{~mm} \times 10 \mathrm{~mm} \times 3 \mathrm{~mm})$ and, between the slides, an acrylic glass slide containing an oval cavity that created a living space. This nest was placed in a larger plastic box $(100 \mathrm{~mm} \times 100 \mathrm{~mm} \times 30 \mathrm{~mm})$ with paraffin oil-coated walls that prevented ants from escaping. Colonies had a reproductive queen and brood and were kept in a climate chamber at $25^{\circ} \mathrm{C}$ with a 12-h:12-h light/dark cycle. Colonies were fed twice a week with honey and a cricket and were provided with water ad libitum. Temnothorax colonies can occasionally contain queen-worker "intercastes," but they are very rare (Okada et al. 2013) and none were found in our colonies.

\section{Part 1: measuring the body size distribution}

All workers from four recently collected colonies (colony size, 59-76 workers) were individually transferred into a petri dish covered with graph paper (square sizes of $1 \mathrm{~mm}^{2}$ ), which served as a scale. Each ant was photographed three times with a Nikon D7000 camera (AF-S Micro Nikkor 105 mm lens), mounted on a tripod and at a constant distance of approx. $30 \mathrm{~cm}$ above the petri dish. We measured total body length and head width of ants using ImageJ 1.46 and averaged the values from the three photos. Body length and head width were highly correlated $(r=0.84, N=262$, Pearson correlation: $p<0.0001$ ), but body length is used as our measure of body size in this study because it is easier to measure due to the small size of the ants.

\section{Part 2: body size and walking speed}

We collected 3-4 large (2.75-3.25 mm body length) and 3-4 small $(2.25-2.65 \mathrm{~mm})$ workers from each of eight colonies as they were walking outside their artificial nest and put them in small groups in a plastic arena $(17.8 \times 11.8 \times 4.7 \mathrm{~cm})$. The walls were coated with Fluon to prevent ants from escaping. The floor was covered with graph paper that allowed us to measure walking speed. Body size was measured as described above. After a 10-min acclimatization period, ants were filmed (Canon Legria HF R706) from above ( $30 \mathrm{~cm}$ distance) for $10 \mathrm{~min}$ as they were exploring the arena. The walking speed $(\mathrm{cm} / \mathrm{s})$ of ants was determined using the object detection and tracking software AnTracks (www.antracks.org). Three uninterrupted 20-s sequences (i.e. periods when ants did not interact with another ant, stand still or walk along a wall) were averaged for each ant.

\section{Part 3: body size and tandem running}

We used 22 colonies (range of 56-100 workers) and performed 1 (12 colonies) or 2 (10 colonies) emigrations per colony. One day before an emigration, nests containing colonies were placed in an emigration arena $(31.2 \times 22.3 \times$ $4.7 \mathrm{~cm}$ ). The walls were again coated with Fluon, and the floor was covered with graph paper. On a test day, a new empty nest was placed in the emigration arena, $20 \mathrm{~cm}$ from the original nest. To motivate the colony to move to this new nest, the old nest was destroyed by gently removing the lid (see e.g. Mallon and Franks 2000; Pratt 2008). We filmed emigrations with the camera (Panasonic HC-VX878 4K) positioned $70 \mathrm{~cm}$ above the arena. Filming ended when colonies stopped performing tandem runs, usually within $2 \mathrm{~h}$ after the destruction of the old nest.

We measured the body size of tandem leaders and followers by averaging three still images per ant taken from the video recordings (the correlation coefficient $(r)$ among individual images was on average 0.93 , i.e. measurement 1 vs. measurement 2 of the same ant, measurement 1 vs. measurement 3 of the same ant). The still images were taken at the beginning of a tandem run, so that the person taking the measurements was unaware whether a tandem run was going to be successful or not. Additionally, we measured total duration of successful tandem runs, the pair's rate of progress ("speed," $\mathrm{cm} / \mathrm{s}$ ) and the walked distance by the pair $(\mathrm{cm})$ using AnTracks. The walked distance is a measure of how direct tandem runs are. A tandem was considered successful (i) if the pair reached the nest entrance together or (ii) if the follower reached the nest entrance less than $1 \mathrm{~min}$ after a contact loss. The latter situation referred to break-ups that were close to the new nest entrance, e.g. along the edge of the new nest, was included because the tandem leader played a critical role in the discovery of the new nest by the follower. Only tandem runs 
from the old to the new nest were analysed, i.e. forward tandem runs. Ants were not marked, and to avoid measuring the same ant more than once (pseudoreplication), each pair was removed from the experiment immediately after the leader contacted the new nest. Ants that were part of unsuccessful tandem runs were also removed. On average, $8.6 \pm 4.25$ ants per colony were removed by the end of the experiment.

\section{Part 4: body size and task}

We measured the body size of five extranidal workers (presumably ants scouting for food or nest sites) and five intranidal workers (presumably nurses) from each of ten recently collected colonies. To make sure that some ants left the colony to explore the environment, colonies were starved 10-14 days. Extranidal workers were collected when they were encountered outside their artificial nest. Afterwards, the nest was opened and ants that sat on the brood pile or carried brood items were captured (intranidal workers). These ants were considered nursing workers. Each ant was photographed 3 times as described above.

\section{Statistical analysis}

All statistical analyses were performed in R 3.4 ( $\mathrm{R}$ Development Core Team 2016). For part 1, we quantified the worker size distribution and explored if body length showed significant skewness or kurtosis. For this, we used the methods described by Crawley (2007, pp. 285-289). The values of each colony were first centered $($ mean $=0)$ and then combined to test overall patterns. To test if ant size affects walking speed (part 2), we used a general linear mixedeffects (LME) model with colony as random effect to control for the non-independence of data points from the same colony (Zuur et al. 2009). Size class was used as the fixed-effect. To analyse the effects of leader and follower body size differences on tandem running (part 3), both generalized linear mixed-effects models (GLMMs) and general LME models were used. GLMMs were used when the distribution of the response variable was binomial (success: yes or no), whereas LME models were used to test the effects on speed, duration and distance. We tested both the relative size difference (leader-follower, i.e. positive values mean that leaders were larger, and negative values indicate that followers were larger) and the absolute size difference (|leader-follower|, i.e. values always positive) as the predictors. To confirm the findings of the mixed-model regarding tandem success while controlling for potential colony effects, we compared the body size differences of failed tandem runs with successful tandem runs from the same colony using a paired $t$ test. For this, all tandem runs from colonies that had both successful and failed tandem runs were included. Additionally, we tested if the order of a tandem run (e.g. first, second and third; tandem run) during a trial affected tandem success.

\section{Results}

\section{Part 1: body size distribution}

Worker body length varied from 2.25 to $3.34 \mathrm{~mm}$ (2.68 \pm 0.16 , mean $\pm \mathrm{StDev}, N=262$ ) in the four measured colonies (Fig. 1). Head width varied from 0.48 to $0.67 \mathrm{~mm}(0.58 \pm$ $0.03)$. The within colony coefficient of variation $(\mathrm{CV})$ for body length was $0.054 \pm 0.01$ ( $N=4$ colonies). Body size distribution was unimodal, suggesting that $T$. nylanderi does not have distinct physical castes (Fig. 1a). The Shapiro-Wilk test suggests a significant deviation from normality ( $W=0.98472$, $p=0.007)$. Body size also showed significant positive skew ( $t$ value $=2.04, p=0.02)$ and significant kurtosis $(t$ value $=3.55$, $p=0.0002$ ).

\section{Part 2: body size and walking speed}

To test whether body size predicts walking speed, we quantified the walking speed of ants belonging to two size categories, large and small, as they explored a small arena. Ants from the large group were $\sim 17 \%$ larger in body length than ants from the small group and walked significantly $(+30 \%)$ faster than ants from the small group (Fig. 1b) $(0.74 \pm 0.3 \mathrm{~cm} / \mathrm{s}$ vs. $0.57 \pm 0.26 \mathrm{~cm} / \mathrm{s}$, LME model: $t$ value $=2.32, p=0.025$ ). This indicates that larger ants walk faster in this particular experimental situation.

\section{Part 3: body size and tandem running}

We analysed 95 tandem runs from 22 colonies; $56 \%$ were successful. The size of tandem leaders did not correlate with the size of their followers (LME model, values centered for each colony: $t$ value $=-1.36, p=0.18$ ).

We then tested if the relative and absolute size difference predicted tandem success. Absolute size difference, but not relative size difference, significantly affected tandem success (Fig. 2) (absolute difference: GLMM, $z$ value $=-4.22$, $p<0.0001$; relative difference: $z$ value $=-0.7, p=0.49$ ). Thus, larger size differences were associated with a low chance of tandem success, but it did not matter if the larger ant was the leader or the follower (Fig. 2c). We also tested a model that included the absolute size difference and, in addition, the two predictors: "follower body length" and "leader body length." This would reveal if body length per se affects tandem success rate in addition to size differences. However, we found that only the absolute size difference, but not the body size of leaders and followers, affected tandem success rate $(G L M M$, absolute difference: $z$ value $=-4.12$, 
Fig. 1 a Worker size (body length) density distribution in T. nylanderi colonies. Grey lines show the individual density distribution functions for the four colonies. b The walking speed of individual workers depending on their size. Bars show means \pm 1 standard error

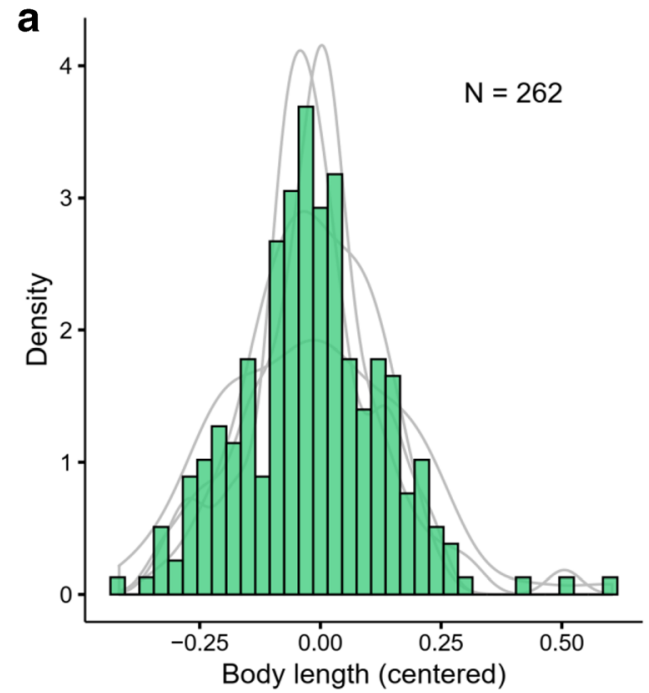

$p<0.0001$; leader body length: $z$ value $=-0.21, p=0.85$; follower body length: $z$ value $=0.82, p=0.42$ ) .

A paired $t$ test confirmed that ant pairs of failed tandem runs differed more in size $(0.2 \pm 0.08 \mathrm{~mm})$ than pairs of successful tandem runs $(0.1 \pm 0.05 \mathrm{~mm})$ from the same colony ( $t$ value $=3.64, d f=14, p=0.0027$, $N=15$ colonies with both failed and successful tandem runs). The order of a tandem run during a trial did not affect success rate (GLMM, $z$ value $=-0.19, p=0.85$ ).

We did not find any links between absolute and relative size difference and the speed, duration and walked distance of successful tandem runs (Table 1). We then explored whether the average size of ants in tandem (average of leader and follower) affects tandem success and tandem speed, but found no relationship (GLMM, success: $z$ value $=1.31, p=0.19$; LME model, speed: $t$ value $=1.34, p=0.18$ ).

\section{Part 4: body size and task}

We tested whether workers caught outside of their nest (potential scouts for food sources or nest sites) differ in size from workers that were captured inside their nest and in close proximity to brood (potential nurses). Extranidal workers (2.4 \pm $0.2 \mathrm{~mm} ; N=50, \mathrm{CV}=0.083$ ) were significantly larger than intranidal workers $(2.32 \pm 0.18 \mathrm{~mm} ; N=50, \mathrm{CV}=0.078)$ in ten recently collected colonies (LME model: $t$ value $=2.12$, $p=0.037$ ). This is consistent with other Temnothorax species (see "Discussion").

\section{Discussion}

We found that larger body size differences among interacting ants were associated with a high probability of tandem run

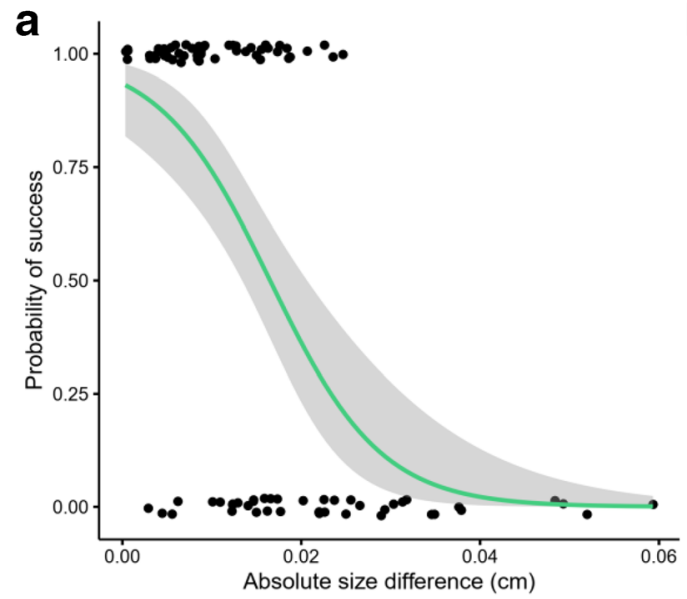

Fig. 2 Probability that tandem runs were successful depending on the body length difference between leader and follower $(\mathbf{a}, \mathbf{b})$ and on whether the larger ant was the leader or the follower (c). a Note that all values are either 1 (success) or 0 (failure) but that jitter was used to better visualize the data
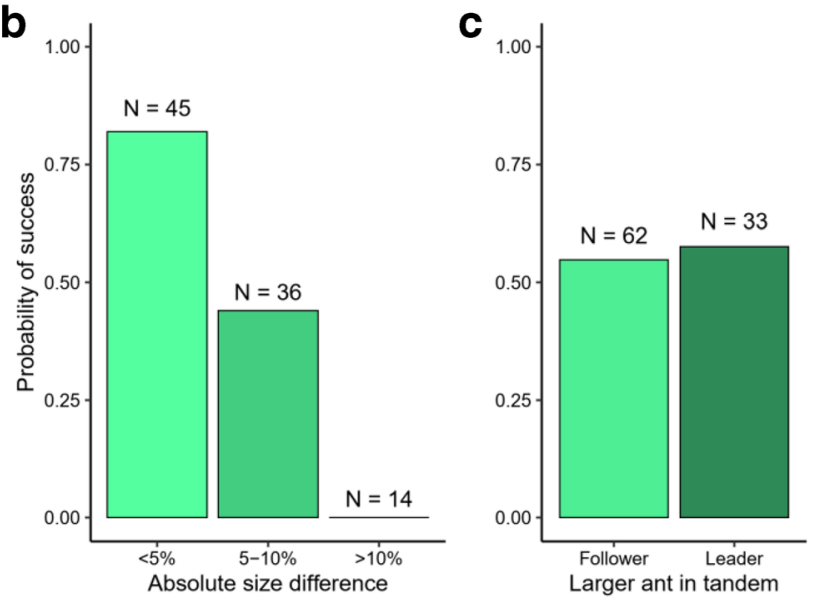

points. Grey areas show the $95 \%$ confidence interval. b The same data as in a, but the success probability for three different body length differences between the leader and the follower is shown. A value of 5\% means that one of the ants was $5 \%$ smaller or larger than its partner 
Table 1 The effects of relative and absolute size difference on the tandem success rate of all tandem runs $(N=95)$

\begin{tabular}{|c|c|c|c|c|c|c|c|c|}
\hline & \multicolumn{2}{|c|}{ Success rate } & \multicolumn{2}{|c|}{ Duration (s) } & \multicolumn{2}{|c|}{ Distance $(\mathrm{cm})$} & \multicolumn{2}{|c|}{ Speed $(\mathrm{cm} / \mathrm{s})$} \\
\hline & $z$ value & $p$ & $t$ value & $p$ & $t$ value & $p$ & $t$ value & $p$ \\
\hline Relative size difference: $\mathrm{L}-\mathrm{F}$ & -0.7 & 0.49 & 0.57 & 0.57 & 0.38 & 0.71 & -0.92 & 0.36 \\
\hline Absolute size difference: $|\mathrm{L}-\mathrm{F}|$ & -4.22 & $<0.0001$ & 1.06 & 0.30 & 0.89 & 0.38 & -1.05 & 0.30 \\
\hline
\end{tabular}

Additionally, the speed $(\mathrm{cm} / \mathrm{s})$, duration (s, square root-transformed) and distance (cm, log-transformed) walked of successful tandem runs $(N=53)$ are shown. Linear mixed-effects models with colony were used as a random effect (GLMMs and LMEs)

$L$ leader, $F$ follower failure. Tandem runs were unsuccessful when the leaderfollower size difference exceeded $10 \%$, whereas $\sim 80 \%$ of tandem runs were successful when ants differed less than $5 \%$ in body length (Fig. 2b). Speed, duration and distance travelled of the remaining successful tandem runs were not affected by body size differences. Our results suggest that size difference predict tandem success irrespective of whether the larger ant is the leader or the follower. One explanation could be that ants differing in size differ in their walking speed (Fig. 1b). Ants walking in a tandem run frequently need to accelerate and decelerate in order to maintain pair cohesion (Franks and Richardson 2006). Body size could affect the speed at which ants perform these changes and, thus, the probability of short contact losses. In this case, body size differences would not affect communication or signaling per se, but the ability of ants to stay together during this recruitment communication process. Body size is likely to be linked to various sensory, physiological or cognitive traits (e.g. Waddington 1989; Spaethe et al. 2007; Grüter et al. 2017b) that could affect the probability of tandem break-ups. While our data do not allow us to identify the trait or traits that are responsible for break-ups, they do suggest that failure is more common if leader and follower show phenotypic differences in the responsible trait or traits.

The tandem leaders in our study were probably relatively inexperienced because only the first tandem run of a pair was analysed. Previous research has shown that tandem leaders perform more successful tandem runs with increasing experience (Franklin et al. 2012; Glaser and Grüter 2018), and it would be interesting to explore how size differences affect tandem runs of more experienced tandem leaders. It could be, for example, that leaders can learn how to guide tandem followers that differ greatly in size.

Even though some lost followers may discover the new nest by themselves (Pratt 2008; Franks et al. 2010), unsuccessful tandem runs often represent a loss of time because lost followers require more time to discover a resource or they have to return to their nest following a break-up (Franks and Richardson 2006; Basari et al. 2014b; Grüter et al. 2018). Furthermore, a break-up could leave followers in unknown and dangerous locations. Alternatively, repeated partial tandem runs could represent a strategy to gain information about the direction to a new nest site. Break-ups could also provide opportunities to discover different food sources or nest sites, which could be beneficial in a dynamic environment (see e.g. Deneubourg et al. 1983; Beekman and Dussutour 2009). However, given the search time of $T$. nylanderi followers after a break-up (Glaser and Grüter 2018) and the time ants have to wait inside the nest until they find a new leader, it is doubtful that this strategy would save time compared to performing one complete tandem run.

One observation that could indicate a strategy to reduce the risk of break-ups is that extranidal workers were larger than intranidal workers. This is consistent with findings in two other Temnothorax species (Herbers and Cunningham 1983; Westling et al. 2014). Allocating larger workers to outside tasks is likely to decrease the probability that very large ants perform tandem runs with very small ants (the same could be achieved by allocating only small workers to outside tasks). Other potential advantages of larger extranidal workers could be an increased foraging rate due to their greater walking speed, greater foraging ranges (Ness et al. 2004, but see Westling et al. 2014) or a reduced risk of predation by certain predators.

Waddington (1989) hypothesized that size variation negatively affects waggle dance communication in honeybees because bees of different sizes may judge distances to food sources differentially. These costs of size variation could in turn select for low intracolonial size variation (see also Waddington et al. 1986; Sauthier et al. 2017). While strong evidence for this is lacking, our finding that the size-frequency distribution in T. nylanderi colonies shows significant kurtosis (a leptokurtic distribution) indicates that there might be selection against body sizes that deviate strongly from the mean. Worker size variation in T. nylanderi (CV of $\sim 5 \%$ ) is similar to what has been found in T. rugatulus, which also performs tandem running (Westling et al. 2014). A comparison of worker size variation in species that use tandem running versus closely related species without tandem running could provide further evidence to support or challenge the hypothesis that the need for efficient recruitment communication selects for low intracolonial worker size variation. It would also be interesting to quantify worker size variation in ants with a very high success rate of tandem runs ( $90 \%)$, such as Diacamma 
indicum (Kaur et al. 2017), to explore whether worker size variation is particularly small in these species. Worker size in T. nylanderi is determined by food quantity but also depends on rearing temperature and colony size (Molet et al. 2017). The degree of worker size variation could be modified either by nurse workers providing more constant or variable conditions (e.g. food amount) (Segers et al. 2015) or by larvae modifying their developmental response to external factors (Rissing 1987).

In Apis mellifera, dancing bees were more likely to be followed by bees of similar size (Waddington 1989). We found no correlation between leader and follower size in T. nylanderi. This could be explained by an inability of ants to accurately estimate the size of potential partners or by time costs that result from waiting for tandem partners of similar size. Such waiting time costs are likely to be larger in small colonies, such as in T. nylanderi, than in larger colonies, such as in honeybees (Anderson and Ratnieks 1999). Waggle dancing and tandem running are similar in that both require direct interactions between the signaler and the receiver. It is possible that behaviours involving direct interactions (e.g. cooperative transport, group recruitment or adult carrying) are more prone to being negatively affected by size variation than indirect forms of interactions, such as pheromone trails.

Body size variation is often linked to different roles in insect colonies. The most impressive examples are found in species with distinct physical worker castes (or sub-castes) performing different tasks (Wilson 1971; Oster and Wilson 1978; Hölldobler and Wilson 2009). However, most species display moderate, continuous worker size variation (Oster and Wilson 1978) and it is often not clear whether size variation has adaptive value at colony level or whether it could indicate constraints, such as seasonal variability in food availability. For example, bumblebees show moderate and continuous intracolonial size variation (Goulson et al. 2002; Couvillon et al. 2010) and size is linked to the probability to perform certain tasks (Goulson et al. 2002; Spaethe and Weidenmüller 2002), but experimentally manipulating the body size variation in colonies did not affect colony performance in Bombus impatiens (Jandt and Dornhaus 2014). Similarly, two recent studies using $T$. nylanderi found that experimentally reducing worker size variation did not affect colony performance in the laboratory and the field (Colin et al. 2017; Honorio et al. 2020). This highlights that the effects of variation may not be straightforward and may remain hidden until colonies experience challenging conditions. Furthermore, while variation in some traits may be beneficial in the context of particular tasks, e.g. temperature regulation (Jones et al. 2004), variation in other traits or in the context of other tasks (e.g. communication tasks) may be inconsequential or even negative. In the latter case, colonies would have to trade-off the costs and benefits of variation and, as a result, measuring colony traits such as biomass or brood production would miss important consequences of worker diversity because it averages positive and negative effects. Another problem of colony-level analysis is that natural selection might affect phenotypic variation only in particular sub-sets of colony members, e.g. the foragers. Future research can help identify the conditions and contexts that make variation an asset or a problem for insect societies and those where worker variation is simply the result of naturally occurring variation in environmental conditions, without having any fitness consequences for colonies.

Acknowledgments We thank Francisca Segers and the three anonymous reviewers for comments on a previous version of the manuscript.

Funding S.M.G. and C.G. were funded by the Deutsche Forschungsgemeinschaft (DFG) (GR 4986/1-1).

Data availability Raw data are available as an online supplement.

\section{Compliance with ethical standards}

Conflict of interest The authors declare that they have no conflict of interest.

Ethical approval No licences or permits were required for this research.

Open Access This article is licensed under a Creative Commons Attribution 4.0 International License, which permits use, sharing, adaptation, distribution and reproduction in any medium or format, as long as you give appropriate credit to the original author(s) and the source, provide a link to the Creative Commons licence, and indicate if changes were made. The images or other third party material in this article are included in the article's Creative Commons licence, unless indicated otherwise in a credit line to the material. If material is not included in the article's Creative Commons licence and your intended use is not permitted by statutory regulation or exceeds the permitted use, you will need to obtain permission directly from the copyright holder. To view a copy of this licence, visit http://creativecommons.org/licenses/by/4.0/.

\section{References}

Alshebli BK, Rahwan T, Woon WL (2018) The preeminence of ethnic diversity in scientific collaboration. Nat Commun 9:5163

Anderson C, Ratnieks FLW (1999) Task partitioning in insect societies. I. Effect of colony size on queueing delay and colony ergonomic efficiency. Am Nat 154:521-535

Basari N, Laird-Hopkins BC, Sendova-Franks AB, Franks NR (2014a) Trail laying during tandem-running recruitment in the ant Temnothorax albipennis. Naturwissenschaften 101:549-556

Basari N, Bruendl AC, Hemingway CE, Roberts NW, Sendova-Franks AB, Franks NR (2014b) Landmarks and ant search strategies after interrupted tandem runs. J Exp Biol 217:944-954

Baudier KM, Ostwald MM, Grüter C, Segers FHID, Roubik DW, Pavlic TP, Pratt SC, Fewell JH (2019) Changing of the guard: mixed specialization and flexibility in nest defense (Tetragonisca angustula). Behav Ecol 30:1041-1049

Beckers R, Goss S, Deneubourg J-L, Pasteels JM (1989) Colony size, communication and ant foraging strategy. Psyche 96:239-256 
Beekman M, Dussutour A (2009) How to tell your mates: costs and benefits of different recruitment mechanisms. In: Jarau S, Hrncir M (eds) Food exploitation by social insects: ecological, behavioral, and theoretical approaches. CRC Press, Taylor \& Francis Group, Boca Raton, pp 115-134

Beshers SN, Traniello JFA (1994) The adaptiveness of worker demography in the attine ant Trachymyrmex septentrionalis. Ecology 75: $763-775$

Billick I (2002) The relationship between the distribution of worker sizes and new worker production in the ant Formica neorufibarbis. Oecologia 132(2):244-249

Billick I, Carter C (2007) Testing the importance of the distribution of worker sizes to colony performance in the ant species Formica obscuripes Forel. Insect Soc 54(2):113-117

Colin T, Doums C, Péronne R, Mole M (2017) Decreasing worker size diversity does not affect colony performance during laboratory challenges in the ant Temnothorax nylanderi. Behav Ecol Sociobiol 71(6):92

Couvillon MJ, Jandt JM, Duong N, Dornhaus A (2010) Ontogeny of worker body size distribution in bumble bee (Bombus impatiens) colonies. Ecol Entomol 35:424-435

Crawley MJ (2007) The R book. John Wiley \& Sons Ltd, Chichester

Deneubourg JL, Pasteels JM, Verhaeghe JC (1983) Probabilistic behaviour in ants: a strategy of errors? J Theor Biol 105:259-271

Dornhaus A, Chittka L (1999) Evolutionary origins of bee dances. Nature 401(6748):38-38

Franklin EL (2014) The journey of tandem running: the twists, turns and what we have learned. Insect Soc 61:1-8

Franklin EL, Robinson EJH, Marshall JAR, Sendova-Franks AB, Franks NR (2012) Do ants need to be old and experienced to teach? J Exp Biol 215(8): 1287-1292

Franks NR, Richardson TO (2006) Teaching in tandem-running ants. Nature 439:153

Franks NR, Richardson TO, Keir S, Inge SJ, Bartumeus F, SendovaFranks AB (2010) Ant search strategies after interrupted tandem runs. J Exp Biol 213:1698-1708

Freeman RB, Huang W (2015) Collaborating with people like me: ethnic coauthorship within the United States. J Labor Econ 33(S1):S289 S318

Glaser S, Grüter C (2018) Ants (Temnothorax nylanderi) adjust tandem running when food source distance exposes them to greater risks. Behav Ecol Sociobiol 72:40

Goulson D, Peat J, Stout J, Tucker J, Darvill B, Derwent LC, Hughes WOH (2002) Can alloethism in workers of the bumblebee, Bombus terrestris, be explained in terms of foraging efficiency? Anim Behav 64:123-130

Grüter C, Menezes C, Imperatriz-Fonseca VL, Ratnieks FLW (2012) A morphologically specialized soldier caste improves colony defence in a Neotropical eusocial bee. Proc Natl Acad Sci U S A 109:11821186

Grüter C, Segers FHID, Menezes C, Vollet-Neto A, Falcon T, von Zuben L, Bitondi MMG, Nascimento FS, Almeida EAB (2017a) Repeated evolution of soldier sub-castes suggests parasitism drives social complexity in stingless bees. Nat Commun 8:4

Grüter C, Segers FHID, Santos LLG, Hammel B, Zimmermann U, Nascimento FS (2017b) Enemy recognition is linked to soldier size in a polymorphic stingless bee. Biol Lett 13:20170511

Grüter C, Wüst M, Cipriano A, Nascimento F (2018) Tandem recruitment and foraging in the ponerine ant Pachycondyla harpax (Fabricius). Neotrop Entomol 47:742-749

Herbers JM, Cunningham M (1983) Social organization in Leptothorax longispinosus Mayr. Anim Behav 31(3):759-771

Hölldobler B, Wilson EO (2009) The superorganism: the beauty, elegance, and strangeness of insect societies. W. W. Norton \& Company, New York
Honorio R, Doums C, Molet M (2020) Manipulation of worker size diversity does not affect colony fitness under natural conditions in the ant Temnothorax nylanderi. Behav Ecol Sociobiol 74(8): 104. https://doi.org/10.1007/s00265-020-02885-2

Horwitz SK, Horwitz IB (2007) The effects of team diversity on team outcomes: a meta-analytic review of team demography. J Management 33(6):987-1015

Jandt JM, Dornhaus A (2014) Bumblebee response threshold and body size: does worker diversity increase colony performance? Anim Behav 87:97-106

Jones JC, Myerscough MR, Graham S, Oldroyd BP (2004) Honey bee nest thermoregulation: diversity promotes stability. Science 305 : 402-404

Kaur R, Joseph J, Anoop K, Sumana A (2017) Characterization of recruitment through tandem running in an Indian queenless ant Diacamma indicum. R Soc Open Sci 4(1):160476

Levine SS, Apfelbaum EP, Bernard M, Bartelt VL, Zajac EJ, Stark D (2014) Ethnic diversity deflates price bubbles. Proc Natl Acad Sci U S A 111(52):18524-18529

Mallon EB, Franks NR (2000) Ants estimate area using Buffon's needle. Proc R Soc B 267:765-770

Matsuura K, Kuno E, Nishida T (2002) Homosexual tándem running as selfish herd in Reticulitermes speratus: novel antipredatory behavior in termites. J Theor Biol 214:63-70

Mattila HR, Seeley TD (2007) Genetic diversity in honey bee colonies enhances productivity and fitness. Science 317:362-364

Mertl AL, Traniello JFA (2009) Behavioral evolution in the major worker subcaste of twig-nesting Pheidole (Hymenoptera: Formicidae): does morphological specialization influence task plasticity? Behav Ecol Sociobiol 63:1411-1426

Modlmeier AP, Foitzik S (2011) Productivity increases with variation in aggression among group members in Temnothorax ants. Behav Ecol 22:1026-1032

Möglich M, Maschwitz U, Hölldobler B (1974) Tandem calling: a new kind of signal in ant communication. Science 186:1046-1047

Molet M, Péronnet R, Couette S, Canovas C, Doums C (2017) Effect of temperature and social environment on worker size in the ant Temnothorax nylanderi. J Therm Biol 67:22-29

Ness J, Bronstein J, Andersen AN, Holland J (2004) Ant body size predicts dispersal distance of ant-adapted seeds: implications of smallant invasions. Ecology 85(5):1244-1250

Noland M, Moran T, Kotschwar BR (2016) Is gender diversity profitable? Evidence from a global survey. Working Papers Series 16:3

Okada Y, Plateaux L, Peeters C (2013) Morphological variability of intercastes in the ant Temnothorax nylanderi: pattern of trait expression and modularity. Insect Soc 60(3):319-328

Oldroyd BP, Fewell J (2007) Genetic diversity promotes homeostasis in insect colonies. Trends Ecol Evol 22:408-413

Oster GF, Wilson EO (1978) Caste and ecology in the social insects. Princeton University Press, Princeton

Porter SD, Tschinkel WR (1985) Fire ant polymorphism: the ergonomics of brood production. Behav Ecol Sociobiol 16:323-336

Powell S (2016) A comparative perspective on the ecology of morphological diversification in complex societies: nesting ecology and soldier evolution in the turtle ants. Behav Ecol Sociobiol 70:10751085

Powell S, Franks NR (2005) Caste evolution and ecology: a special worker for novel prey. Proc R Soc B 272:2173-2180

Pratt SC (2008) Efficiency and regulation of recruitment during colony emigration by the ant Temnothorax curvispinosus. Behav Ecol Sociobiol 62:1369-1376

R Development Core Team (2016) R: a language and environment for statistical computing. R Foundation for Statistical Computing, Vienna

Richardson TO, Sleeman PA, McNamara JM, Houston AI, Franks NR (2007) Teaching with evaluation in ants. Curr Biol 17:1520-1526 
Rissing SW (1987) Annual cycles in worker size of the seed-harvester ant Veromessor pergandei (Hymenoptera: Formicidae). Behav Ecol Sociobiol 20:117-124

Sauthier R, I'Anson Price R, Grüter C (2017) Worker size in honeybees and its relationship with season and foraging distance. Apidologie 48(2):234-246

Segers FHID, Menezes C, Vollet-Neto A, Lambert D, Grüter C (2015) Soldier production in a stingless bee depends on rearing location and nurse behaviour. Behav Ecol Sociobiol 69:613-623

Spaethe J, Weidenmüller A (2002) Size variation and foraging rate in bumblebees (Bombus terrestris). Insect Soc 49:142-146

Spaethe J, Brockmann A, Halbig C, Tautz J (2007) Size determines antennal sensitivity and behavioural threshold to odors in bumblebee workers. Naturwissenschaften 94:733-739

Sumner S, Pereboom JJ, Jordan WC (2006) Differential gene expression and phenotypic plasticity in behavioural castes of the primitively eusocial wasp, Polistes canadensis. Proc R Soc B 273(1582):19-26

Tian L, Zhou X (2014) The soldiers in societies: defense, regulation, and evolution. Int J Biol Sci 10:296-308

Van Knippenberg D, Schippers MC (2007) Work group diversity. Ann Rev Psychol 58:515-541
Waddington KD (1989) Implications of variation in worker body size for honey bee recruitment system. J Insect Behav 2:91-103

Waddington KD, Herbst LH, Roubik DW (1986) Relationship between recruitment systems of stingless bees and within-nest worker size variation. J Kans Entomol Soc 59:95-102

Westling J, Harrington K, Bengston S, Dornhaus A (2014) Morphological differences between extranidal and intranidal workers in the ant Temnothorax rugatulus, but no effect of body size on foraging distance. Insect Soc 61(4):367-369

Wilson EO (1959) Communication by tandem running in the ant genus Cardiocondyla. Psyche 66:29-34

Wilson EO (1971) The insect societies. Harvard University Press, Cambridge

Zuur AF, Ieno EN, Walker NJ, Saveliev AA, Smith GM (2009) Mixed effects models and extensions in ecology with R. Springer, New York

Publisher's note Springer Nature remains neutral with regard to jurisdictional claims in published maps and institutional affiliations. 